\title{
Tungsten erosion and redeposition in the all-tungsten divertor of ASDEX Upgrade
}

M. Mayer ${ }^{\mathrm{a}}$, M. Andrzejczuk ${ }^{\mathrm{d}}$, R. Dux ${ }^{\mathrm{a}}$, E. Fortuna-Zalesna ${ }^{\mathrm{d}}$, A. Hakola ${ }^{\mathrm{c}}$, S. Koivuranta ${ }^{\mathrm{c}}, \mathrm{K}$. Krieger $^{\mathrm{a}}$, K.J. Kurzydlowski ${ }^{\mathrm{d}}$, J. Likonen ${ }^{\mathrm{c}}$, G. Matern ${ }^{\mathrm{a}}$, R. Neu ${ }^{\mathrm{a}}$, G. Ramos ${ }^{\mathrm{b}}$, M. Rasinski ${ }^{\mathrm{a}, \mathrm{d}}$, V. Rohde $^{\mathrm{a}}$, K. Sugiyama ${ }^{\mathrm{a}}$, A. Wiltner ${ }^{\mathrm{a}}$, W. Zielinski ${ }^{\mathrm{d}}$, and ASDEX-Upgrade team

${ }^{a}$ Max-Planck-Institut für Plasmaphysik, EURATOM Association, Boltzmannstr. 2, 85748 Garching, Germany

${ }^{\mathrm{b}}$ CICATA-Qro, Instituto Politécnico Nacional, Querétaro, México

${ }^{\mathrm{c}}$ VTT Materials for Power Engineering, EURATOM Association, P.O.B. 1000, FI-02044 VTT, Finland

${ }^{\mathrm{d}}$ Faculty of Materials Science and Engineering, Warsaw University of Technology, Association EURATOM-IPPLM, 02-507 Warsaw, Poland

Net erosion and deposition of tungsten in the ASDEX Upgrade divertor were determined after the 2007 campaign by using thin tungsten marker stripes. ASDEX Upgrade had full-tungsten plasmafacing components during this campaign. The inner divertor and the roof baffle were net $\mathrm{W}$ deposition areas with a maximum deposition of about $1 \times 10^{18} \mathrm{~W}$-atoms $/ \mathrm{cm}^{2}$ in the private flux region below the inner strike point. Net erosion of $\mathrm{W}$ was observed in the whole outer divertor, with the largest erosion close to the outer strike point. Only a small fraction of the tungsten eroded in the main chamber and in the outer divertor was found in redeposits in the inner divertor, while a large fraction was either redeposited at unidentified places in the main chamber or has formed dust.

PACS numbers: 52.40.Hf, 52.55.Fa, 82.80.Yc, 82.80.Ms

\section{Introduction}

Global erosion, redeposition and transport of first-wall materials have been studied extensively in ASDEX Upgrade during the last seven years, using both post-mortem surface analysis of tiles and samples [1, 2, 3, 4] and spectroscopy [5,6]. For post-mortem analysis specially prepared divertor or limiter tiles are used, which contain thin marker stripes for erosion/deposition measurements. These marker stripes are analysed before and after exposure. In addition regular tiles are analysed after exposure. Long-term samples are installed at the vessel walls or in remote areas without direct plasma contact $[7,8,9,10,11]$. 
All samples are typically exposed during one discharge campaign, and they provide information about the campaign-integrated net material erosion/deposition pattern. Spectroscopic measurements provide time-resolved information about the influx of material during individual discharges or even during their different phases, such as edge-localized mode (ELM)-resolved studies [6]. However, because the spectroscopically determined material influx is a superposition of fluxes due to recycling and erosion, it is generally difficult to derive the net erosion from spectroscopic data. Spectroscopy and post-mortem surface analysis therefore provide complementary information.

During the last seven years ASDEX Upgrade was converted from a carbon dominated to a full-tungsten machine [12]. The stepwise replacement of carbon by tungsten plasma-facing components offered the unique possibility to identify net carbon and tungsten sources by monitoring changes in the amount of redeposited material [4].

ITER is foreseen to use carbon strike points during the initial hydrogen ( $\mathrm{HH})$ operation phase, but a full-tungsten divertor during the later deuterium (DD) and deuterium-tritium (DT) operation phases. For DEMO, a full-tungsten solution is probably the only option due to the high erosion yields of beryllium and carbon. ASDEX Upgrade allows already today to study tungsten erosion and transport in a full tungsten machine. This paper presents results about tungsten erosion and deposition during the 2007 operation phase of ASDEX Upgrade.

\section{Experimental}

\subsection{Plasma operation}

During the 2007 campaign the divertor IIc was used, the cross-section of the divertor is shown in figure 1. The design of the divertor was slightly changed from the previous divertor IIb configuration in order to allow failsafe $\mathrm{W}$ cooling. All tiles consisted of W-coated fine grain graphite. The coatings were prepared by physical vapour deposition (PVD) and their thicknesses ranged from 3 to $5 \mu \mathrm{m}$. For the outer target (tile 1) a $200 \mu \mathrm{m}$ thick $\mathrm{W}$ coating deposited by vacuum plasma spraying (VPS) was used. A detailed description of the development of $\mathrm{W}$ coatings for ASDEX Upgrade is available in [13,14,15].

The total discharge time with lower X-point divertor configuration was 2620 s during the 2007 campaign. No boronizations were performed during this campaign, and no hydrogen $(\mathrm{H})$ discharges were carried out at the end of the campaign.

\subsection{Post-mortem analyses}


A full poloidal section of divertor tiles in sector 12 was coated with marker stripes [16]. The marker consisted of about $300 \mathrm{~nm} \mathrm{~W}$ on all inner divertor tiles (6A, 6B, 5, 4), all roof baffle tiles (9A, 9B, 9C, 9D), and on tile 10. Outer divertor tiles 2, 3A and 3B were coated with 500$600 \mathrm{~nm} \mathrm{~W}$, and the outer strike point tile 1 had a $1.5 \mu \mathrm{m}$ thick marker stripe. A $20 \mathrm{~mm}$ wide stripe remained uncoated on all tiles, i.e. consisted of the carbon substrate. This stripe was intended for measuring $\mathrm{W}$ redeposition. A view of tile 5 is shown in Fig. 2.

The tiles were analysed with Rutherford-backscattering (RBS) using 2.5 and $3.0 \mathrm{MeV}$ protons at $165^{\circ}$ before and after installation in ASDEX Upgrade. The analyzing beam spot diameter was $1.8 \mathrm{~mm}$. The backscattering spectra were evaluated with the program SIMNRA [17], using non-Rutherford scattering cross-sections from $[18,19]$. Depth profiles of D, C and W were measured by secondary ion mass spectrometry (SIMS) using $10 \mathrm{keV} \mathrm{Ar}^{+}$as primary ion beam. The SIMS depth scale was calibrated by measuring the depth of the sputter crater with a profiler after the measurement. The morphology of the tile surfaces was investigated by secondary electron microscopy (SEM) using secondary and backscattered electrons. The specimens for transmission electron microscopy (TEM) observations were prepared using a Focused Ion Beam (FIB) system (Hitachi FB-2100) [20]. Observations were carried out using a high resolution scanning electron microscope HRSEM Hitachi S5500 with a STEM detector at $30 \mathrm{kV}$.

The SIMS analyses at VTT [21] were performed using a double focussing magnetic sector instrument (VG Ionex IX-70S). A $5 \mathrm{keV} \mathrm{O}_{2}{ }^{+}$primary ion beam with a current of approximately $500 \mathrm{nA}$ was used and the currents of secondary ions at $m / z$ values of $1\left({ }^{1} \mathrm{H}\right), 2$ $\left({ }^{2} \mathrm{H}\right), 10(\mathrm{~B}), 12\left({ }^{12} \mathrm{C}\right), 13\left({ }^{13} \mathrm{C}\right), 52(\mathrm{Cr})$ and $184(\mathrm{~W})$ were profiled. The beam was rasterscanned across an area of $300 \times 430 \mu^{2}$ and the measurements were repeated at 2-5 points on each sample. A $10 \%$ electronic gate and a $1 \mathrm{~mm}$ optical gate were used in all the measurements to remove the effects from the walls of the sputter craters. The depth scale was calibrated by measuring the depth of a few craters after their SIMS analyses using a profilometer. The qualitative compositions of the analyzed layers were determined by integrating each elemental ion-current peak until the background level was reached.

\section{Net tungsten erosion and redeposition}

The net erosion or net deposition of tungsten is defined as the difference of the amounts of tungsten before and after exposure, i.e., $\mathrm{E}_{\text {net }}=\mathrm{N}_{\text {after }}-\mathrm{N}_{\text {before, }}$, where $\mathrm{N}_{\text {before }}$ is the amount of tungsten (in atoms $\mathrm{cm}^{-2}$ ) before exposure and $\mathrm{N}_{\text {after }}$ the amount after exposure. Erosion is 
negative, while net deposition (due to tungsten arriving from the main chamber or other divertor areas) is positive. As gross erosion we can define the amount of tungsten that was eroded, taking into account that some tungsten was deposited from other areas: $E_{\text {gross }}=\mathrm{N}_{\text {after }}$ $\mathrm{N}_{\text {before }}-\mathrm{N}_{\text {deposit }}$. $\mathrm{N}_{\text {deposit }}$ is the amount of tungsten deposited on the uncoated carbon stripe.

The positions of the inner and outer strike points are shown in Fig. 3 (top). The time histogram of strike point positions was derived from the magnetic reconstruction. The inner strike point was mostly on tile 4, with very few discharges having the strike point on tile 5 or 9B. The outer strike point was always on tile 1. The diamonds show the integrated ion fluence to the outer strike point tile 1 , as derived from Langmuir probe data.

The change of the amount of tungsten on the marker stripes (i.e. net erosion/deposition) is shown in Fig. 3 (bottom). The amounts of $\mathrm{W}$ before and after exposure were determined with an accuracy of about $3 \%$. Because the change of the amount of $\mathrm{W}$ is the difference between these numbers and the change can be small compared to the initial amount of $\mathrm{W}$, the error for determining the change of the amount of $\mathrm{W}$ can get large. Typical error bars are shown in Fig. 3 for all tiles. Tile 1 has larger absolute error bars than other tiles because the marker stripe on this tile was thicker.

The inner divertor is a net tungsten deposition area. The largest deposition is observed on tile 4 below the strike point position in the private flux region. Tiles 6A, 6B and 5 show not only a poloidal, but also a toroidal distribution of tungsten deposition due to shadowing by neighbouring tiles. This is shown for tile 5 in Fig. 3 for the plasma-exposed and the plasmashadowed part of the tile. This toroidal distribution was also observed in the occurrence and density of electrical arc tracks [22], see also Fig. 2. The dip in $\mathrm{W}$ deposition at $\mathrm{s} \sim 210 \mathrm{~mm}$ is in the area with strong arc activity (upper right hand side of the tile in Fig. 2). Tiles 6A and 6B also showed many arc tracks.

The roof baffle (tiles 9) is also a net re-deposition area for W, mainly on tiles 9A, 9B and 9C. Tile 9B showed a large number of arc tracks, which are probably responsible for the dip in the $\mathrm{W}$ deposition at $\mathrm{s} \sim 710 \mathrm{~mm}$.

Almost the whole outer divertor is a net $\mathrm{W}$ erosion area. The largest erosion is observed at the outer strike point tile 1 , where also the largest ion fluxes were observed. However, the adjacent tile 2 also shows a remarkable erosion. The maximum $\mathrm{W}$ erosion at the outer strike point is about $7 \times 10^{14} \mathrm{~W}$-atoms $/ \mathrm{cm}^{2} \mathrm{~s}=0.1 \mathrm{~nm} / \mathrm{s}$. This is comparable to the observed erosion of $\mathrm{W}$ markers in the carbon divertor during the 2004-2005 operational phase, which was $>0.06 \mathrm{~nm} / \mathrm{s}$ [3]. The lowest few $\mathrm{cm}$ of tile 1 (close to the corner with tile 10) show a small 
deposition area. This small deposition area was already observed in the carbon deposition pattern in the carbon dominated machine [2].

\section{Morphology of redeposited layers in the inner divertor}

A transmission electron micrograph of the lower corner of tile 4 (at $\mathrm{s} \sim 510 \mathrm{~mm}$ ) is shown in Fig. 4. This area is exceptional, because it is the only area in the divertor with still remaining re-deposition of carbon [4]. The re-deposited layer has a stratified structure with a thickness of 500-700 nm. The bottommost layers were deposited at the beginning of the discharge campaign and appear bright, i.e. they have a smaller absorption for transmitted electrons and consist mainly of low-Z elements. As could be shown by SIMS measurements (see Fig. 5), and nuclear reaction analysis (NRA) [4] the low-Z elements are mainly carbon and deuterium, with some intermixed $\mathrm{W}$. The top layers were deposited at the end of the discharge campaign and appear darker due to higher electron absorption. They therefore contain a higher concentration of $\mathrm{W}$ than the layers deposited at the beginning of the campaign.

Scanning electron micrographs of the surface of tile 6A are shown in Fig. 6. The shown area was initially uncoated and consisted of fine-grain graphite. After exposure the whole area is

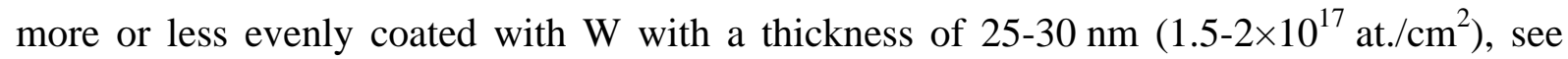
Fig. 3.

\section{Morphology of erosion areas in the outer divertor}

Scanning electron micrographs from the outer divertor area with the highest $\mathrm{W}$ erosion are shown in Fig. 7. The initial marker thickness was $1500 \mathrm{~nm}$, and the mean erosion in this area was about $250 \mathrm{~nm}$. The marker was fully eroded and the underlying carbon substrate was exposed at the leading surfaces of the microscopically rough surface, while the $\mathrm{W}$ layer still covered the carbon substrate at shadowed surfaces ('leading' and 'shadowed' surfaces are relative to the magnetic field). This indicates a very inhomogeneous erosion of the $\mathrm{W}$ marker, with a maximum erosion at plasma exposed areas which is more than 5 times larger than the mean erosion of the layer. Such an inhomogeneous erosion was already observed at tungsten marker layers in the outer divertor of JET [23], and in previous campaigns with marker layers in the outer divertor of ASDEX Upgrade [3]. This inhomogeneous erosion is difficult to understand, because the Larmor radius of both impurity and deuterium ions is larger than $100 \mu \mathrm{m}$ : This is much larger than the surface roughness of a few $\mu \mathrm{m}$, so that for the gyrating ions the surface should appear almost smooth. A possible explanation would be erosion by fast neutral particles, which don't have a gyro-motion. As was already shown in [6], the 
erosion of $\mathrm{W}$ in the outer divertor is mainly due to ELMs, and it is difficult to imagine how large fluxes of fast neutral particles can be created during ELMs. This inhomogeneous erosion therefore remains a mystery.

The percentage of the surface area with full tungsten erosion and exposure of the underlying carbon substrate versus the mean erosion of $\mathrm{W}$ as fraction of the initial marker coating thickness is shown in Fig. 8 for W marker stripes from the outer strike point tile of JET [23] and ASDEX Upgrade. The ASDEX Upgrade data points were obtained at different poloidal positions of tile 1 . The surface is still fully covered with $\mathrm{W}$ if the mean $\mathrm{W}$ gross erosion is smaller than $10-20 \%$ of the initial coating thickness. If the mean $\mathrm{W}$ gross erosion exceeds 10 $20 \%$ of the initial coating thickness, then on some fraction of the surface full erosion of the W coating is observed. This fraction increases approximately linearly with the mean erosion. If about $50 \%$ of the initial $\mathrm{W}$ coating thickness has been eroded, then on about $40-50 \%$ of the surface area the coating is missing and the underlying carbon is exposed. The initial thickness of the $\mathrm{W}$ marker therefore must be at least 5 to 10 times larger than the mean gross $\mathrm{W}$ erosion in order to prevent total erosion of the marker on microscopic leading surfaces. For thinner layers the W marker will be fully eroded and the carbon substrate will be uncovered on some fraction of the surface. This inhomogeneous erosion therefore imposes a minimum coating thickness, if exposure of the underlying carbon substrate should be avoided. The initial coating thickness of the outer strike point tile 1 at ASDEX Upgrade is $200 \mu \mathrm{m}$, which is thick enough to avoid carbon exposure even after several discharge campaigns.

\section{Global tungsten transport}

The tungsten influx from different sources was investigated spectroscopically in [6]. The main findings were:

1. The largest $\mathrm{W}$ influxes are always observed in the outer divertor. The $\mathrm{W}$ influx increases strongly during ELMs, and $40-90 \%$ of the $\mathrm{W}$ influx is observed during ELMs. In between ELMs the influx increases with increasing electron temperature.

2. In the main chamber the outboard limiters and the inner heat shield are additional W sources. The W influx from limiters increases with decreasing distance of the SOL to these limiters. The same dependence of $\mathrm{W}$ influx with SOL distance is observed for the inner heat shield.

3. The $\mathrm{W}$ concentration in the plasma centre is independent of the $\mathrm{W}$ divertor source, i.e. a large fraction of the $\mathrm{W}$ eroded in the divertor does not enter the core plasma but must 
be redeposited somewhere. The $\mathrm{W}$ concentration in the plasma centre is influenced by the limiter and heat shield W sources.

The net $\mathrm{W}$ erosion/deposition pattern shown in Fig. 3 can be integrated in order to achieve global numbers for $\mathrm{W}$ erosion/deposition. All numbers are normalized to a "standard" discharge campaign of $3000 \mathrm{~s}$.

1. About $12.8 \mathrm{~g}$ of $\mathrm{W}$ is eroded in the outer divertor. Most of this is eroded from tile 1, but there is also a substantial erosion observed on all other outer divertor tiles. About $0.25 \mathrm{~g}$ was found redeposited on the lowest few centimetres of tile 1 and on tile 10, but this is only a small fraction of the total amount of net eroded W. The majority of net eroded $\mathrm{W}$ is therefore transported out from the outer divertor and redeposited elsewhere.

2. W is eroded in the main chamber from the outboard limiters and the inner heat shield in addition to the $\mathrm{W}$ erosion in the outer divertor. The net $\mathrm{W}$ erosion from these areas is unknown.

3. About $3.4 \mathrm{~g}$ of $\mathrm{W}$ is found in redeposits in the inner divertor, and about $2.0 \mathrm{~g}$ on the roof baffle. This is about $40 \%$ of the net $\mathrm{W}$ erosion in the outer divertor. However, because at least some of this redeposited $\mathrm{W}$ originates from the additional $\mathrm{W}$ sources in the main chamber (from the outboard limiters and the inner heat shield), a large fraction of $\mathrm{W}$ eroded in the outer divertor is finally redeposited at unknown places. This may be either somewhere in the main chamber, or the $\mathrm{W}$ has finally formed dust.

4. About $2 \mathrm{~g}$ of $\mathrm{W}$ is found in dust on the passive stabilizer loop and in the main chamber ports [24]. The largest amount of dust is found below the divertor, but the amount of $\mathrm{W}$ in this dust has not been quantified.

At first sight the net $\mathrm{W}$ erosion/deposition pattern in the full-W machine with $\mathrm{W}$ erosion in the outer and deposition in the inner divertor resembles the carbon erosion/deposition pattern in the carbon-dominated machine, where also erosion in the outer and deposition in the inner divertor was observed [4]. About $3 \mathrm{~g}$ of carbon was eroded in the outer divertor, and about $14 \mathrm{~g}$ carbon was redeposited in the inner divertor and in remote areas in $3000 \mathrm{~s}$ during the 2004/2005 campaign. The main net carbon sources (with > $11 \mathrm{~g}$ per $3000 \mathrm{~s}$ ) were the outboard limiters. However, while for carbon a massive deposition in the inner divertor, only a small deposition in the main chamber, and a small erosion in the outer divertor has been observed, the $\mathrm{W}$ erosion/deposition pattern shows only a small deposition in the inner divertor and a large erosion in the outer divertor. This is a qualitative change in the global erosion/deposition and material transport pattern. 


\section{Conclusions}

Net erosion and deposition of $\mathrm{W}$ was determined in the divertor of ASDEX Upgrade by using W marker stripes during the full-W campaign 2007. The inner divertor and the roof baffle were net $\mathrm{W}$ deposition areas, and about $5.4 \mathrm{~g}$ of $\mathrm{W}$ was deposited during a $3000 \mathrm{~s}$ "standard" discharge campaign. In addition, about $2 \mathrm{~g}$ of $\mathrm{W}$ was found in dust on the passive stabilizer loop and the main chamber ports. The outer divertor is a net $\mathrm{W}$ erosion area, and about $13 \mathrm{~g}$ of $\mathrm{W}$ was eroded in $3000 \mathrm{~s}$. The largest fraction of this eroded $\mathrm{W}$ is transported out from the outer divertor and redeposited at unknown areas, either in the main chamber or as dust below the divertor. While for carbon in ASDEX Upgrade a massive deposition in the inner divertor and a small erosion in the outer divertor is observed, for $\mathrm{W}$ only a small deposition in the inner divertor and a large erosion in the outer divertor is observed. This is a qualitative change of the global divertor erosion/deposition pattern. The $\mathrm{W}$ erosion on technical rough surfaces is very inhomogeneous, and the erosion at leading microscopic surfaces exceeds the mean net erosion by a factor of 5-10. The mechanism for this inhomogeneous erosion is not understood. Due to this inhomogeneous erosion behavior a minimum thickness for the coating is required to avoid exposure of the underlying carbon substrate.

\section{Acknowledgements}

The technical assistance of J. Dorner and M. Fußeder and ion-beam analysis measurements by D. Heim, F. Blobner and Ch. Boehm are gratefully acknowledged. 


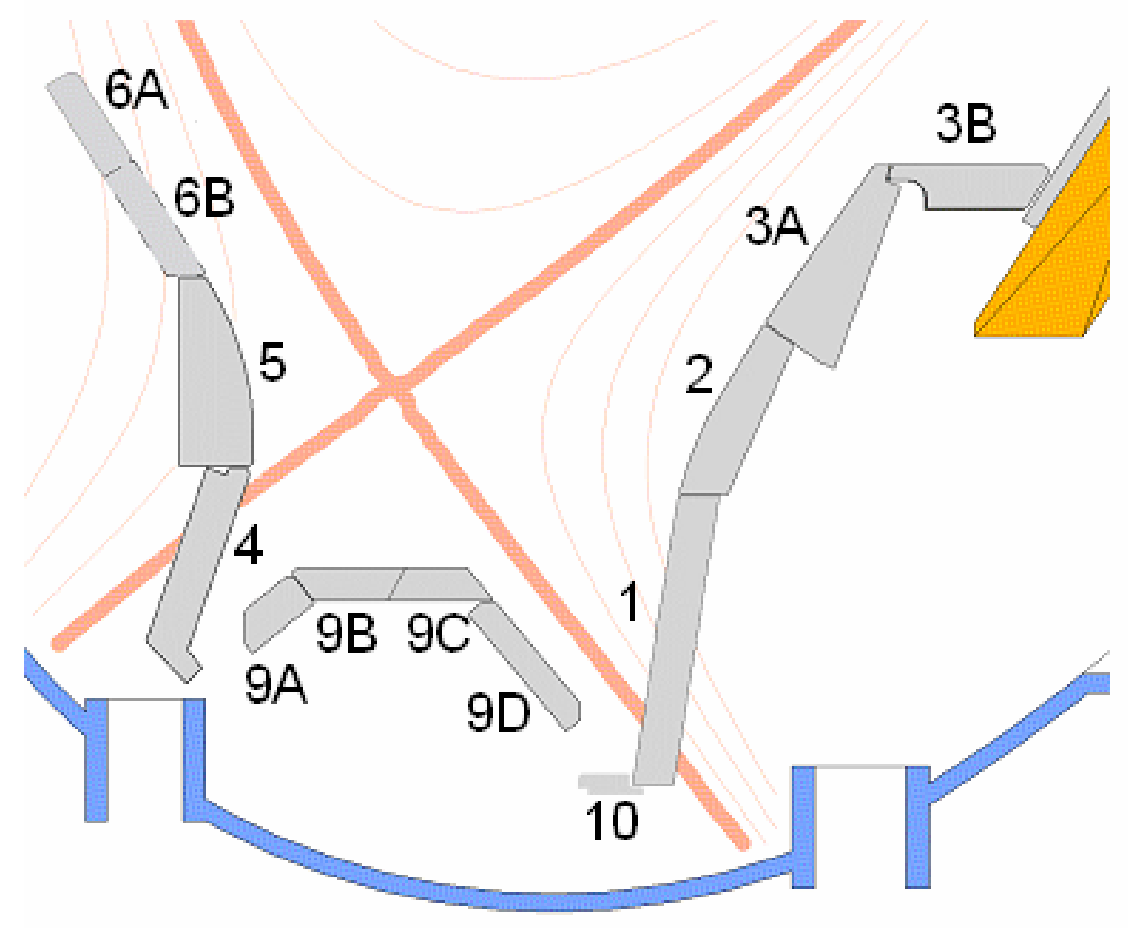

Fig. 1: Cross-sectional view of the ASDEX Upgrade divertor during the 2007 campaign. All tiles consist of PVD-W coated (3- $5 \mu \mathrm{m}$ ) graphite, except for the outer target tile (tile 1) which is VPS-W coated $(200 \mu \mathrm{m})$ graphite. 


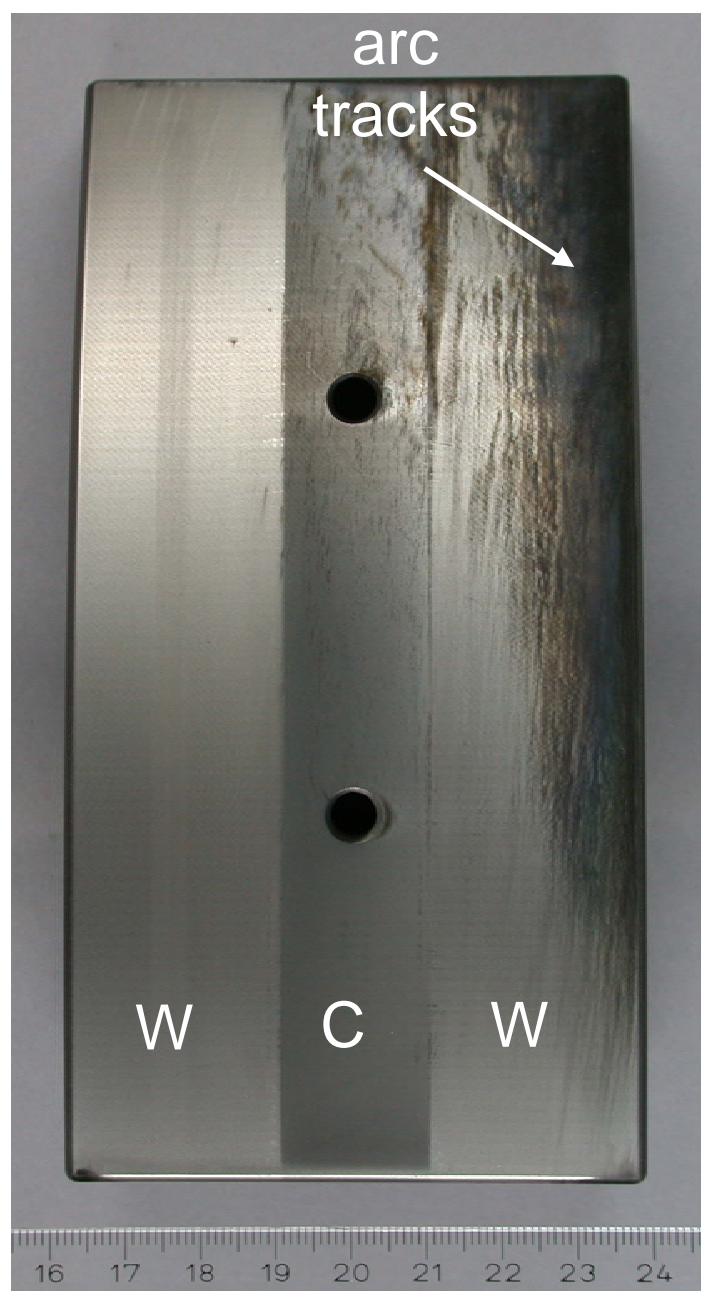

Fig. 2: Marker stripes on inner divertor tile 5 after exposure during the 2007 campaign. The markers consisted of a $300 \mathrm{~nm}$ thick W marker coating and an uncoated carbon area in the middle of the tile. The left hand side of the tile was plasma-shadowed, the right hand side was plasma-exposed. A large number of arc tracks was observed after exposure. 

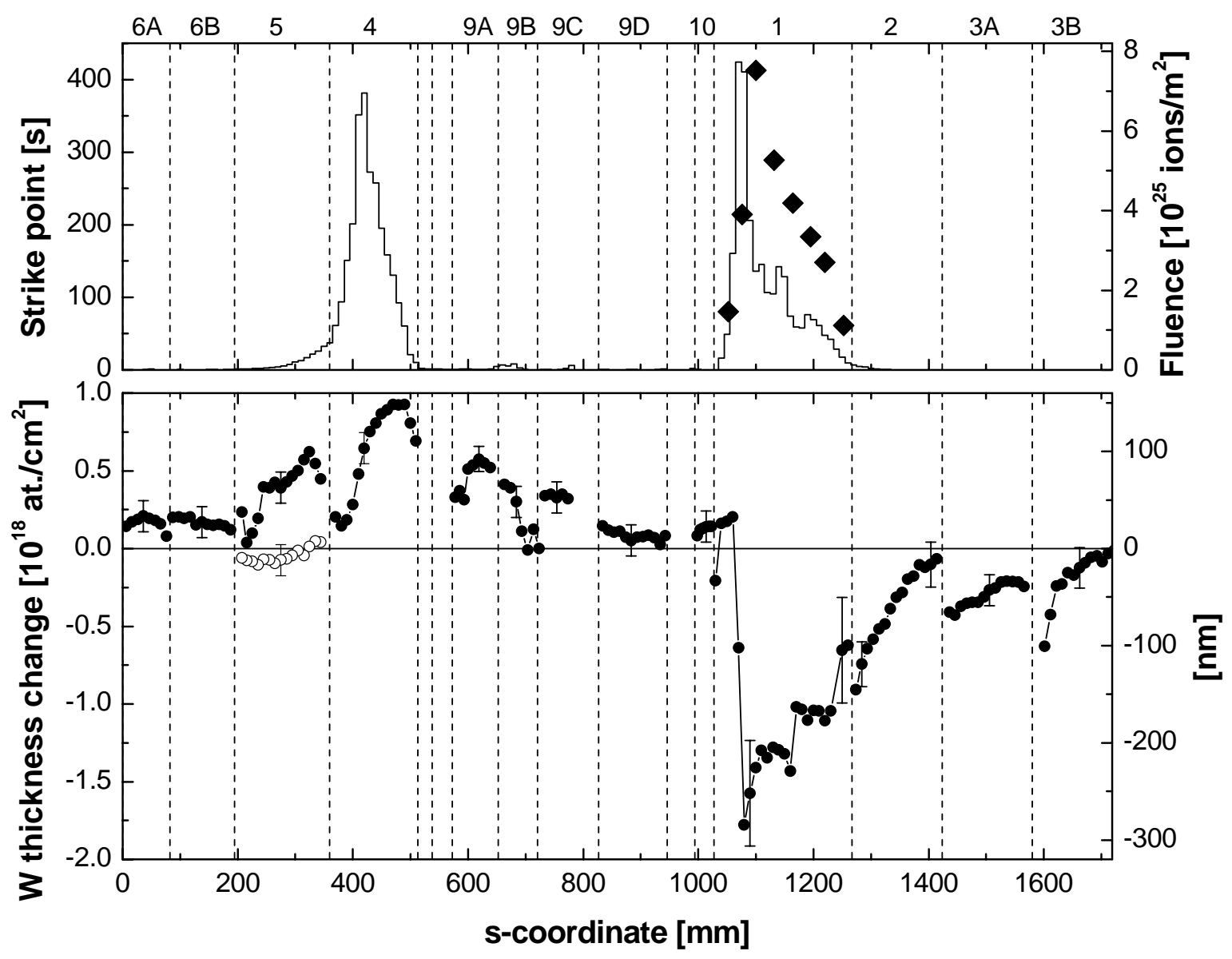

Fig. 3: Top: Distribution of strike point positions during the 2007 discharge campaign. Histogram: time of the strike point at a specific position; diamonds: Campaign-integrated ion fluence, determined by Langmuir probes. Bottom: Change of the amount of tungsten of the marker stripes on the divertor tiles, in $10^{18}$ atoms $/ \mathrm{cm}^{2}$. Negative numbers indicate net erosion, positive numbers net deposition. Typical error bars are indicated for all tiles. Two different toroidal positions are shown for tile 5: Solid dots are for the plasma exposed side which showed also many arc tracks (Fig. 2, right hand side of the tile), hollow dots are for the plasma-shadowed side of the tile (Fig. 2, left hand side of the tile). The scale on the right hand side (in $\mathrm{nm}$ ) is obtained by using the theoretical tungsten density of $19.29 \mathrm{~g} / \mathrm{cm}^{3}$. Tile numbers (see Fig. 1 for the detailed divertor geometry) are indicated at the top. 


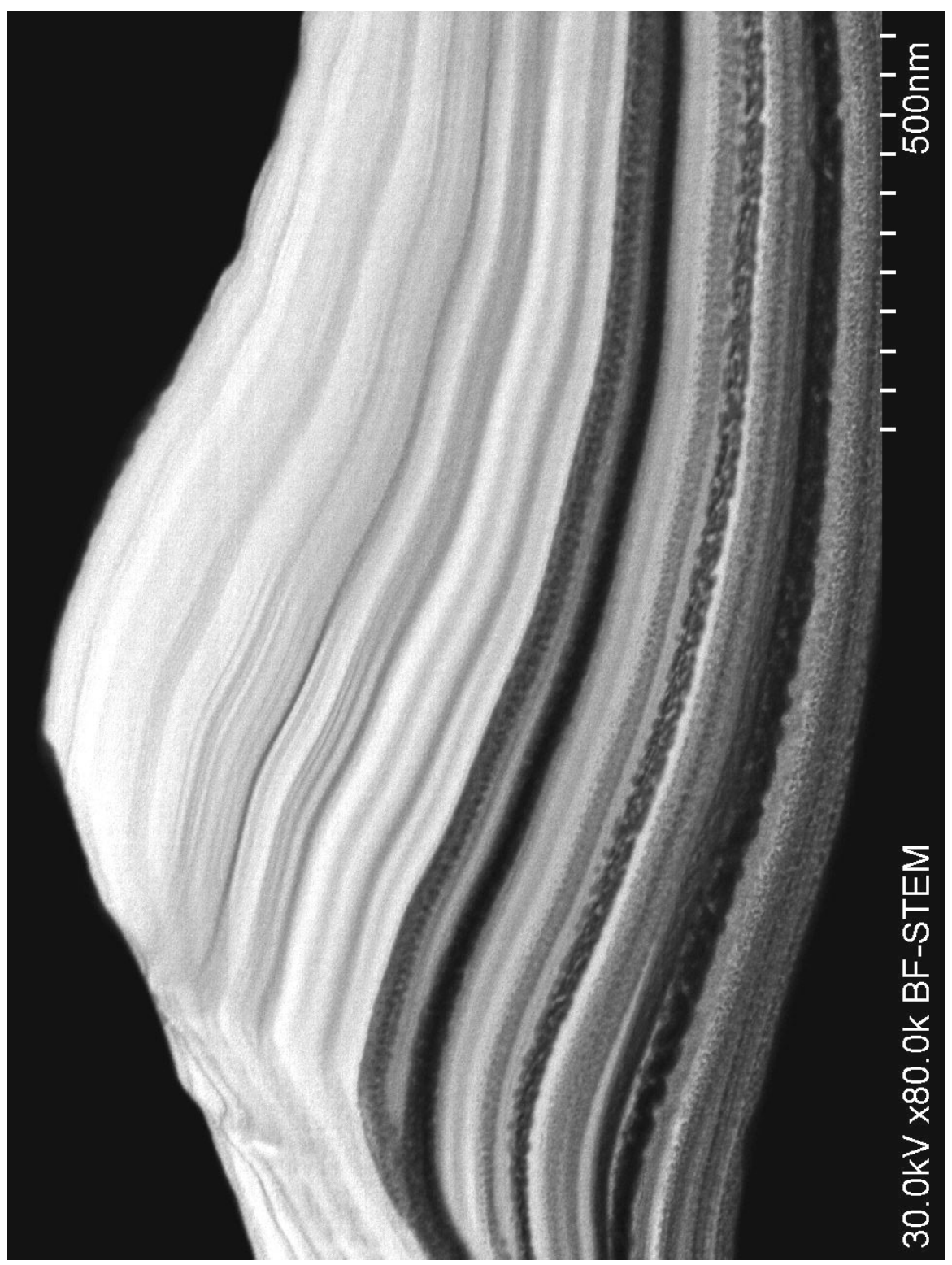

Fig. 4: Transmission electron micrograph from a redeposited layer on tile 4, s 510 mm. LowZ elements (mainly carbon) appear bright, high-Z elements (mainly W) appear dark. The original $\mathrm{W}$ coating of the tile is on the left hand side. It is not transparent for the electrons, so that it appears black. The surface of the redeposited layer (on the right-hand side) was coated with a protective $\mathrm{W}$ coating and therefore also appears black. 


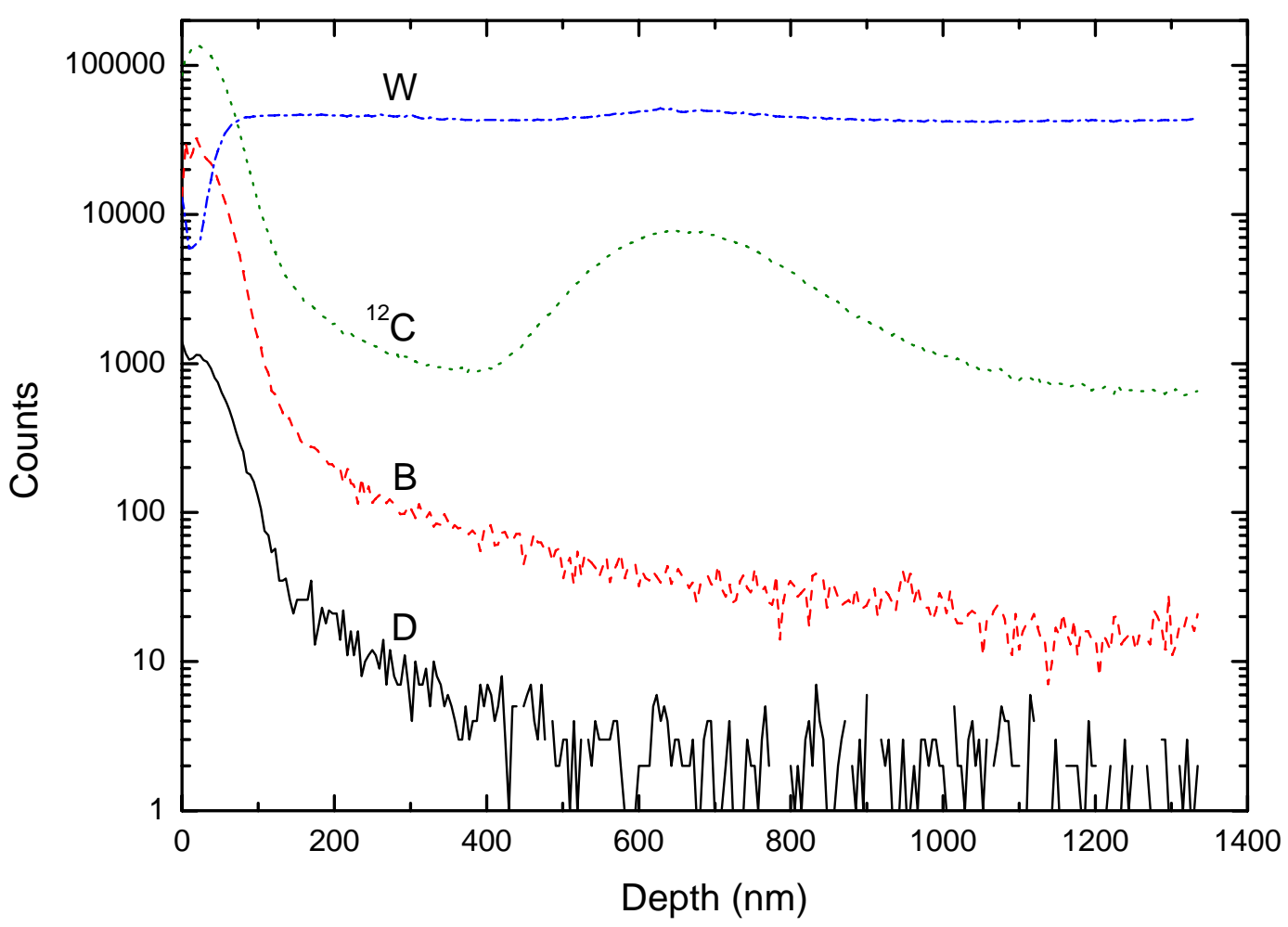

Fig. 5: SIMS depth profiles of D, B, ${ }^{12} \mathrm{C}$ and $\mathrm{W}$ from tile $4 \mathrm{~B}$ (the small "nose" on tile 4, see Fig. 1), $\mathrm{s}=528 \mathrm{~mm}$. The profile is from a regular PVD $\mathrm{W}$ coating with a thickness of more than $3 \mu \mathrm{m} \mathrm{W}$. 

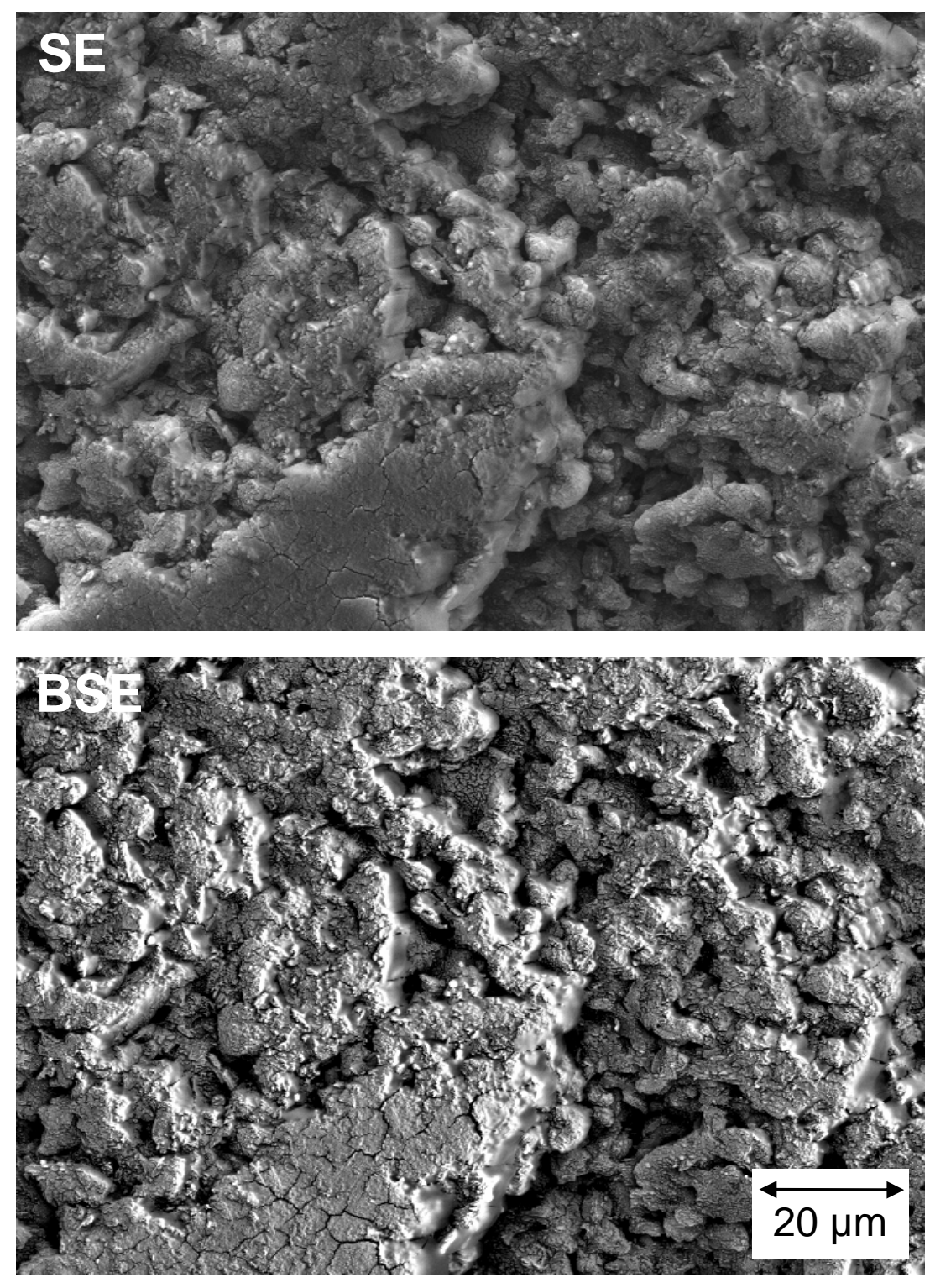

Fig. 6: Scanning electron micrographs of the surface of tile $6 \mathrm{~A}, \mathrm{~s} \sim 40 \mathrm{~mm}$, after exposure. The area was initially uncoated carbon. Top: Secondary electrons (SE); bottom: backscattered electrons (BSE). High-Z elements appear bright in the BSE image. 

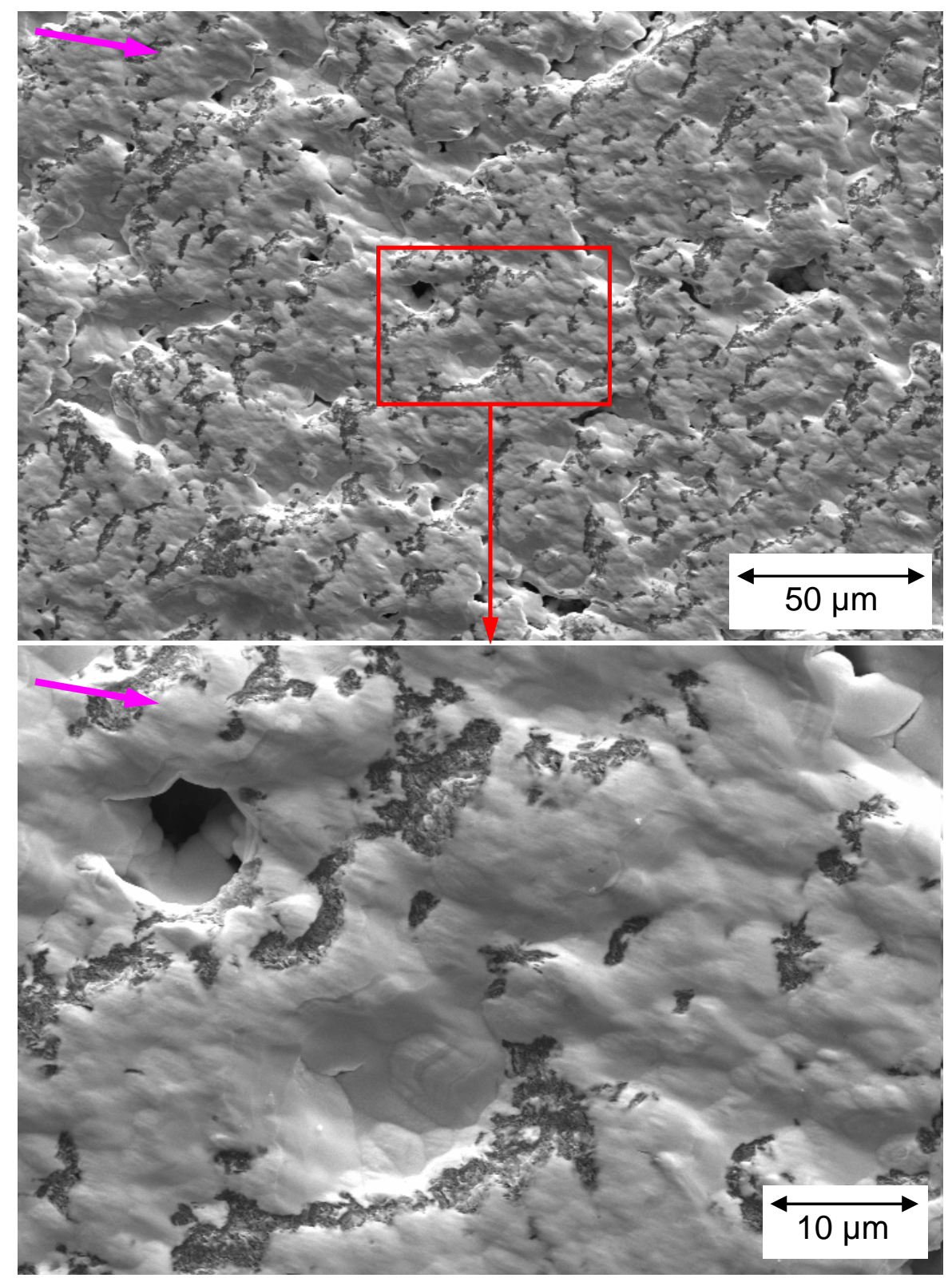

Fig. 7: Scanning electron micrographs of the marker layer after exposure, at two different magnifications. The marker layer is from the strongest erosion area on tile $1, \mathrm{~s} \sim 1100 \mathrm{~mm}$. The initial marker thickness was about $1500 \mathrm{~nm}$, the mean erosion was about $250 \mathrm{~nm}$. The arrows in the upper left corner indicates the direction of the magnetic field. 


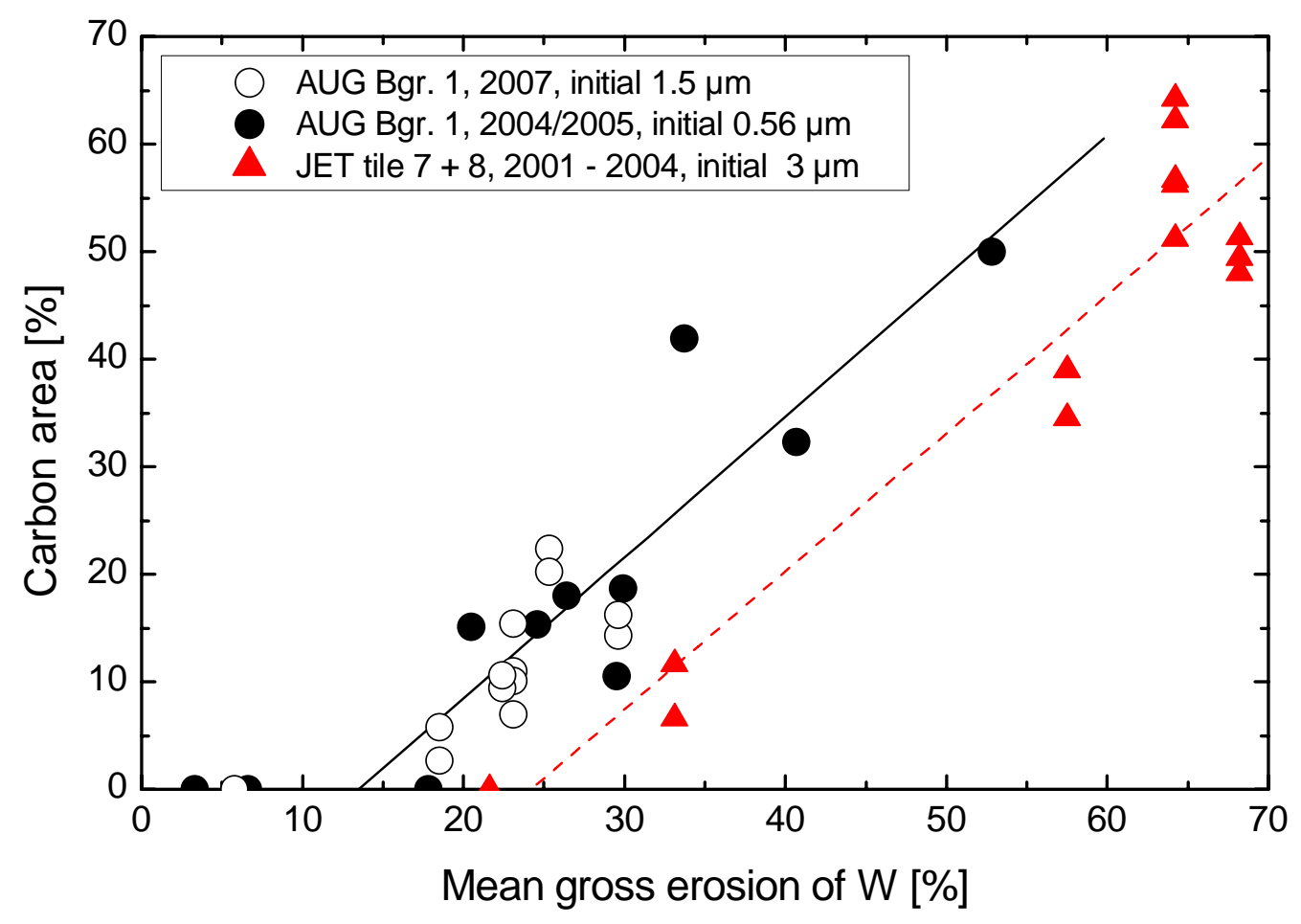

Fig. 8: Percentage of the surface area with full tungsten erosion and exposure of the underlying carbon substrate versus the mean gross erosion of $\mathrm{W}$ as fraction of the initial coating thickness. JET-data were obtained in the 2001 - 2004 campaign on outer strike point tiles 7 and 8 with an initial marker thickness of $3 \mu \mathrm{m}$ W on CFC [23], AUG data were obtained with a marker in the 2004/2005 campaign with an initial thickness of $560 \mathrm{~nm} \mathrm{~W}$ [3] and with the current marker stripes. 
${ }^{1}$ M. Mayer, V. Rohde, T. Pütterich, P. Coad, P. Wienhold, JET-EFDA contributors, and ASDEX Upgrade Team, Physica Scripta T111 (2004) 55

${ }^{2}$ M. Mayer, V. Rohde, J. Likonen, E. Vainonen-Ahlgren, K. Krieger, X. Gong, J. Chen, and ASDEX Upgrade Team, J. Nucl. Mater. 337-339 (2005) 119

${ }^{3}$ M. Mayer, V. Rohde, G. Ramos, E. Vainonen-Ahlgren, J. Likonen, J.L. Chen, and ASDEX Upgrade team, Physica Scripta T128 (2007) 106

${ }^{4}$ M. Mayer, V. Rohde, K. Sugiyama, J.L. Chen, X. Gong, C. Hopf, J. Likonen, S. Lindig, R. Neu, G. Ramos, E. Vainonen-Ahlgren, A. Wiltner, and ASDEX Upgrade Team, J. Nucl. Mater. 390-391 (2009) 538

${ }^{5}$ A. Kallenbach, R. Dux, J. Harhausen, C.F. Maggi, R. Neu, T. Pütterich, V. Rohde, K.Schmid, E. Wolfrum, and the ASDEX Upgrade Team, J. Nucl. Mater. 363-365 (2007) 60

${ }^{6}$ R. Dux, V. Bobkov, A. Herrmann, A. Janzer, A. Kallenbach, R. Neu, M. Mayer, H.W. Müller, R. Pugno, T. Pütterich, V. Rohde, A.C.C. Sips, and ASDEX Upgrade Team, J. Nucl. Mater. 390-391 (2009) 858

${ }^{7}$ M. Mayer, V. Rohde, A. von Keudell, and the ASDEX Upgrade Team, J. Nucl. Mater. 313-316 (2003) 429

${ }^{8}$ M. Mayer, V. Rohde and ASDEX Upgrade Team, Nuclear Fusion 46 (2006) 914

${ }^{9}$ M. Mayer, V. Rohde, G. Ramos, E. Vainonen-Ahlgren, J. Likonen, A. Herrmann, R. Neu, and the ASDEX Upgrade Team, Nuclear Fusion 47 (2007) 1607

${ }^{10}$ V. Rohde, H. Maier, K. Krieger, R. Neu, J. Perchermaier, and ASDEX Upgrade Team, J. Nucl. Mater. 290293 (2001) 317

${ }^{11}$ V. Rohde, M. Mayer and ASDEX Upgrade Team, Physica Scripta T103 (2003) 25

${ }^{12}$ R. Neu, V. Bobkov, R. Dux, A. Kallenbach, Th. Pütterich, H. Greuner, O. Gruber, A. Herrmann, Ch. Hopf, K. Krieger, C.F. Maggi, H. Maier, M. Mayer, V. Rohde, K. Schmid, W. Suttrop, and ASDEX Upgrade team J. Nucl. Mater. 363-365 (2007) 52

${ }^{13}$ S. Deschka, C. García-Rosales, W. Hohenauer, R. Duwe, E. Gauthier, J. Linke, M. Lochter, W. Malléner, L. Plöchl, P. Rödhammer, A. Salito, J. Nucl. Mater. 233-237 (1996) 645

${ }^{14}$ H. Maier, J. Luthin, M. Balden, J. Linke, F. Koch, H. Bolt, Surface and Coating Tech. 142-144 (2001) 733.

${ }^{15}$ R. Neu, R. Dux, A. Geier, O. Gruber, A. Kallenbach, K. Krieger, H. Maier, R. Pugno, V. Rohde, S. Schweizer, ASDEX Upgrade Team, Fus. Eng. Des. 65 (2003) 367

${ }^{16}$ S. Lehto, J. Likonen, J. P. Coad, T. Ahlgren, D. E. Hole, M. Mayer, H. Maier, and J. Kolehmainen, Fusion Eng. and Design 66-68 (2003) 241

${ }^{17}$ M. Mayer, SIMNRA User's Guide, Report IPP 9/113, Max-Planck-Institut für Plasmaphysik, Garching, Germany, 1997

${ }^{18}$ A.F. Gurbich, Nucl. Instr. Meth. B 136-138 (1998) 60

${ }^{19}$ A.F. Gurbich, Nucl. Instr. Meth. B 129 (1997) 311

${ }^{20}$ J. Mayer, L.A. Giannuzzi, T. Kamino, and Joseph Michael, MRS Bulletin 32(5) (2007) 400

${ }^{21}$ J. Likonen, E. Vainonen-Ahlgren, L. Khriachtchev, J.P. Coad, M. Rubel, T. Renvall, K. Arstila, D.E. Hole and Contributors to the EFDA-JET Work-programme, J. Nucl. Mater. 377 (2008) 486

${ }^{22}$ A. Herrmann, M. Balden, M. Laux, K. Krieger, H.W. Müller, R. Pugno, V. Rohde, and ASDEX Upgrade team, J. Nucl. Mater. 390-391 (2009) 747

${ }^{23}$ M. Mayer, J. Likonen, J.P. Coad, H. Maier, M. Balden, S. Lindig, E. Vainonen-Ahlgren, V. Philipps and JETEFDA Contributors, J. Nucl. Mater. 363-365 (2007) 101

${ }^{24}$ V. Rohde, M. Balden, and T. Lunt, Phys. Scr. T138 (2009) 014024 